Bond University

Research Repository

\title{
How to Improve Teaching Using Blended Learning
}

\author{
Gepp, Adrian; Kumar, Kuldeep
}

Published in:

Theoretical and Practical Approaches to Innovation in Higher Education

DOI:

10.4018/978-1-7998-1662-1.ch005

Licence:

Other

Link to output in Bond University research repository.

Recommended citation(APA):

Gepp, A., \& Kumar, K. (2019). How to Improve Teaching Using Blended Learning. In L. N. Makewa (Ed.), Theoretical and Practical Approaches to Innovation in Higher Education (pp. 80-90). IGI Global. https://doi.org/10.4018/978-1-7998-1662-1.ch005

\footnotetext{
General rights

Copyright and moral rights for the publications made accessible in the public portal are retained by the authors and/or other copyright owners and it is a condition of accessing publications that users recognise and abide by the legal requirements associated with these rights.
}

For more information, or if you believe that this document breaches copyright, please contact the Bond University research repository coordinator. 


\section{INTRODUCTION}

With the exponential developments in technology, internet, cloud computing and computing facilities, the education delivery scenario is changing very quickly. The traditional chalkboard method has become more or less obsolete. Consistent with our daily routines that rely more and more on electronic devices, both academic staff and students are relying more on electronic learning. It is claimed that blended learning is the present and future of education, but there is no clear cut definition of blended learning. Oliver and Trigwell (2005) concluded that the term blended learning is ill-defined and inconsistently used, while Horn and Staker (Horn \& Staker, 2011; Staker \& Horn, 2012) have defined blended learning as "new model that is student-centric, highly personalised for each learner, and more productive, as it delivers dramatically better results at the same or lower cost". According to Wikipedia (n.d.) blended learning is defined as "an approach to education that combines online educational materials and opportunities for interaction online with traditional place-based classroom methods". In other words, blended learning is considered as a mix of online teaching and face-to-face teaching. In her book, Driscoll defined four different concepts of blended learning (Driscoll, 2002):

1. To use a combination of technology types (such as virtual classrooms, self-paced instruction, streaming video, audio and text) to accomplish an educational goal.

2. To use a combination of pedagogical approaches (such as constructivism, behaviourism and cognitivism) to enhance a learning outcome with or without instructional technology.

3. To combine any form of instructional technology with face-to-face instructor-led education.

4. To combine instructional technology with real-world job tasks to reduce the gap between learning and working.

This chapter discusses popular tools available for blended learning and the effect of blended learning, as well as tools used by the authors to improve teaching in the area of statistics and data analysis.

\section{TOOLS FOR BLENDED LEARNING}

Given so many definitions and the resulting confusion, the authors feel blended learning is just a set of tools or pedagogy that can be used in face-to-face teaching, as well as online teaching. These tools range from simple tools such as PowerPoint, Prezi, YouTube, Facebook, Excel, Google Scholar, Poll Everywhere and iMovie to more complicated ones such as Camtasia, Moodle, Socrative, Quizlet, Lightboard and Coursera.

The 12th Annual Digital Learning Tools Survey was conducted in 2018 and comprised of 2,951 learning professionals from 52 countries worldwide (Hart, 2019). This survey was used to create a list of the top 200 tools in 2018 for learning, which is available at https://www.toptools4learning.com/home/. However only $23 \%$ of the survey respondents were from primary, secondary or tertiary education (Hart, 2019), and so the sub-list "Top 100 Tools for Education" is more relevant here as it focuses on tools used by educators and students in various educational institutions around the world. The list includes both tools that have been purpose made for education such as Blackboard and Google Classroom, as well as those that have been adopted for education such as YouTube and Canva.

The well-established tools of PowerPoint, YouTube and Word take out the top three spots, in order, of the aforementioned list. This also shows that the Microsoft Office Suite is still very popular with Excel also coming in at number 18 on the list. Microsoft OneDrive is also ranked 27 on the list. It is also evident that more professional teachers are using classroom response tools such as Kahoot (ranked 6) and Poll Everywhere (rank 29). In fact, eight such tools made the 2018 Top 100 Tools for Education list and four 
of them (Plickers, Glisser, Wooclap and Slido) are new additions from the previous year's list. Overall, nine tools made the list in 2018 that were not ranked in 2017. Thus, the education sector is adapting and considering new tools, but perhaps not as fast as other sectors of the learning community as 29 tools debuted on the broader "Top 200 Tools for Learning" list. A notable exclusion from the list is EduTouch, an interactive display panel designed specifically for education. This could be because online solutions are preferred to physical infrastructure. It is also noteworthy that while they rank highly in the broader top 200 learning tools list, online course platforms such as Coursera, Lynda and Udemy do not make the list ranked by educators. Although they do not make the list, the authors believe such type of tools will continue to rise in prominence in the education landscape and that universities need to pay close attention.

Learning management systems such as Moodle (rank 16), Canvas (rank 39) and Blackboard (rank 55) remain popular with educators, or at least with management within the educational sector that usually makes the decisions about such software in the authors' experience. A wide variety of tools that support the development of image, audio and video content are also commonly used. Hart (2019) draws particular attention to the new category of tools that assist interactive content development, such as H5P (rank 45), Genially (rank 52) and HiHaHo (rank 59). There are also tools that help educators create animations to support learning such as Powtoon (rank 21) and Moovly (rank 96).

Perhaps surprising to some is that only two social networks made the list, despite ten making the broader 200 list. However, the two are highly ranked with Twitter at number 15 and Facebook ranked 17. As an example, Twitter can be used by nominating a student to tweet key lessons from class or getting students to follow thought-leaders. Tools that assist in facilitating teamwork are also popular with Slack (rank 31), Trello (rank 32) and Microsoft Teams (rank 34) all ranking higher in 2018 than previously.

The top learning tools in a range of categories, as found by the education community in the above survey, are listed below (with a maximum of five shown for each category):

1. Learning platforms \& management systems: Moodle, Canvas, Google Classroom, Blackboard, Desire2Learn

2. Collaborative platforms and tools: Padlet, Slack, Trello, Microsoft Teams, G Suite

3. Document, presentation and spreadsheet tools: PowerPoint, Word, Prezi, Excel, Sway

4. Screenshot \& screencasting tools: Snagit, Camtasia, Screencast-o-matic, Screenflow, Monosnap

5. Image, graphics \& infographics tools: Canva, Piktochart, Unsplash, Adobe Photoshop, GIMP

6. Audio \& video related tools: Audacity, H5P, Genially, WeVideo,

7. Interactive video and content creation tools: H5P, Genially (new), HiHaHo, EdPuzzle, ThinkLink

8. Animated Explainer tools: Powtoon, Moovly, Vyond

9. Audience response tools: Kahoot, Poll Everywhere, Metimeter, Socrative, Plickers

10. Forms, survey and quiz tools: Google Forms, Quizlet, MicrosoftForms, SurveyMonkey

11. E-learning authoring tools: Articulate, Easygenerator, isEazy, Adobe Captivate, Udutu

12. Blog and Web page tools: WordPress, Google Sites, Wix

13. Web resources (and apps): YouTube, Wikipedia, TED Talks/Ed, Vimeo

14. Web search engines: Google, Wolfram Alpha, Google Scholar 


\section{EFFECTS OF BLENDED LEARNING}

While blended learning is clearly becoming more popular, it is important to have an understanding of the effectiveness of the approach. Garrison and Kanuka (2004) emphasised the importance of assessing and evaluating the effectiveness of blended learning with respect to learning outcomes, student satisfaction, retention and achievement. López-Pérez (2011) surveyed of 1,431 students at the University of Granada and concluded that blended learning has a positive effect on reducing dropout rates and in raising exam pass rates. It was also found that the joint effect of blended learning activities has a positive influence on the students' final marks. Earlier, Boyle et al. (2003) conducted a survey of more than 600 students in two higher education institutions using a new blended learning environment and observed a marked improvement in pass rates in both institutions. The blend in this study represented a mixture of traditional and novel elements such as online resources, tutorial support and module organisation. However, O'Toole \& Absalom (2010) conducted a survey of 72 final year undergraduate teacher education students and observed that Information and Communications Technology (ICT) access formats by themselves are of limited benefit in achieving course outcomes and in some cases ICT models can be seen to negatively affect student performance. Kaplanis (2013) believes there are five benefits of blended learning; there is much overlap between his list and the authors' list below.

1. Students are more engaged when using a variety of content types, which can be provided through blended learning. Often a traditional chalkboard style lecture can be boring for subjects such as statistics. However, subjects can be made more interesting by showing videos such as a YouTube video using real-life data or a video produced using a Lightboard (see Figure 1 for an example). Lightboard has allowed the authors to write bright, colourful equations and graphics while facing the camera, which enables pointing and using hands naturally as in a face-to-face lecture. Overall, a variety of blended learning tools can keep the students focused for longer and promote the development of interest in the subject matter.

2. The best way to learn differs between people and blended learning can be used to provide flexibility through availability. For example, the authors have taught a subject in which recordings of lectures are available any time during the course, and recordings of live, interactive tutorial-type sessions are available any time after the session. This on-demand type access to these resources (and others such as problem sets, readings, textbooks) enables students to choose the order in which they access resources to tailor the learning experience to how they learn best. There is also an additional benefit to this approach. In today's rapidly changing environment, students with the knowledge of how they learn effectively have a "future-proof" education that is much more valuable than the typical approach to teaching students whereby they learn static and singularly applicable information such as how to use the latest statistical package.

3. In addition to the flexibility of learning approach, one of the important benefits of blended learning is that it expands learning time. Students can access online learning materials at their time of choice and from any location. In the authors' experience, students often access learning materials at times such as $11 \mathrm{pm}-2 \mathrm{am}$, which is typically not a time at which educators want to teach; online materials provide a solution.

4. Educators can rapidly analyse, review and give feedback to students. Furthermore, online assessment can also be developed that provides immediate feedback. The authors have used Aplia (now MindTap provided by Cengage Learning) to provide interactive, dynamic quizzes that offer multiple real-world versions of the same problem and provide instant tailored feedback to students.

5. Blended learning can save educator time. Quizzes and tests can be taken online and marked by a computer as previously mentioned. Once online resources have been created, they can be used by as many students as possible without incurring extra time expenditure, except complex 
assignment marking which can be done by tutors. A very simple example is that one of the authors provides introductory videos to their subjects so that the administrative and procedural aspects of the subject need not be covered in lectures, thus freeing up more time to focus on subject matter content. Another example is providing a short video on how to use the statistical analysis software being used in the subject, which avoids the educator having to show students individually or try to explain in an email how to use the software. Feedback the authors have received from students also indicates that they prefer this approach as they do not have to worry about appearing stupid for not knowing how to use the software.

Figure 1. Screenshot of Lightboard video used by the authors when teaching about the Normal Distribution.

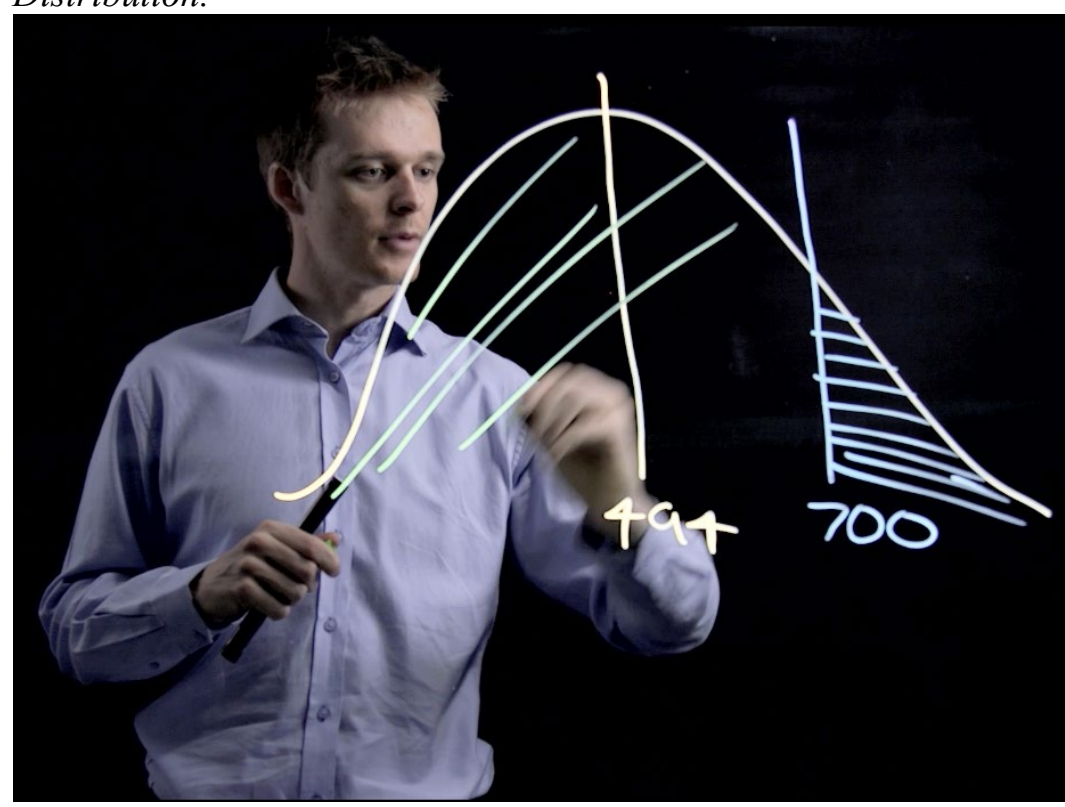

\section{BLENDED LEARNING THROUGH BLACKBOARD}

A common way blended learning is facilitated at many universities is through the Blackboard Learning Management System. It provides an online environment for academic staff members to create and share learning materials including lecture presentation material, quizzes and assignments, data files, audio and video content, web links and more. Blackboard facilitates students accessing learning material before class to prepare and after class to reinforce learning. Students can submit the assignments through Blackboard and simple assignments or quizzes can also be automatically marked. Blackboard sites can be accessed from anywhere at any time, and also has group communication tools to facilitate teamwork. Furthermore, Blackboard, particularly its Gradebook functionality, is also capable of integrating with many other blended learning tools to save time for educators who wish to use multiple blended learning tools.

A typical Blackboard site for a statistics subject at Bond University includes menu items in the five areas listed below.

\section{Basic Information for Students}

a. Announcements: these are made on an as-needed basis. They can be simply posted on the Blackboard site or also pushed to all student email addresses. 
b. Introduction: this is done in text and video format. The video allows students to see the educator and learn more about them before the first class, again so more time can be spent learning the subject matter.

c. Subject Outline: this is the official document that sets formal expectations.

d. Contacts \& Support: this includes information about the educator as well as other support services such as tutors and counselling services. This makes the Blackboard site more of a one-stop shop for students with regards to the subject.

\section{Content}

a. Lecture Content: this includes presentation slides, videos, documents, spreadsheets and more

b. Tutorial Content: this includes question documents, and solution documents including spreadsheets and videos

c. Subject Recordings: this includes video and audio of both lectures and tutorials

d. Resource List: this includes a variety of additional material such as links to recommended library resources that can include newspapers articles, books, journal articles and websites.

e. Discussion Board / Virtual Classroom: sometimes online discussion boards and virtual classrooms are also used.

\section{Assessment}

a. Assessment Items: this includes the assessment details, marking rubrics and any other related information

b. Grades: marks are released to students so they can easily evaluate their standing in this course. Often, mean and standard deviation summary statistics are included so students can assess their performance relative to their peers.

4. Other

a. Interesting Opportunities: this includes a list of related opportunities outside of the subject such as industry speakers.

\section{Policies}
a. Academic Integrity (plagiarism) Policy
b. Academic Regulations
c. Blackboard Help

As an example of multiple tools being used together, Figure 2 shows a video produced by Camtasia, in which simple descriptive statistics are being performed in Excel. At other points in this video, a PowerPoint presentation is used to introduce and summarise the data being analysed in Excel. The authors also integrate Lightboard videos (see Figure 1) into slideshow and spreadsheet presentations using Camtasia to provide a diverse range of learning opportunities for students. Camtasia is also able to incorporate quizzes into the video to add another dimension to blended learning. Video interviews with experts are also used to provide alternative points of view; these are often integrated into other presentations using software such as Camtasia. Such videos may, but do not have to, be used to flip the classroom. When considering whether to use blended learning to flip the classroom, the educator should be aware that flipped classrooms do not benefit all students equally (Chuang, Weng \& Chen, 2018). 
While flipping the classroom has been found to be effective in promoting active learning during class in a number of disciplines, Chuang et al. (2018) use data to show that language students with different personal traits respond differently to flipping the classroom and they suggest implementing multiple strategies for providing online content before a face-to-face class.

Some universities, such as Bond University, have mandated minimum blended learning requirements in official policy. For example, there must be some video content on a Blackboard site to support all face-toface teaching. This reinforces the point made earlier about the value of diverse learning experiences. It does, however, raise issues about whether mandating consistency amongst blended learning resources is beneficial to students who will be exposed to a variety of circumstances in their working career. More research is needed to uncover the answer. The authors suspect that exposing students to variety at university helps to prepare students for the variety they will face at work. Hence, there is a delicate balance between ensuring blended learning resources are used by educators and leaving enough flexibility for educators to choose what works best in their own content area.

Figure 2. Screenshot of Camtasia Video demonstrating using spreadsheet software in a statistics context.

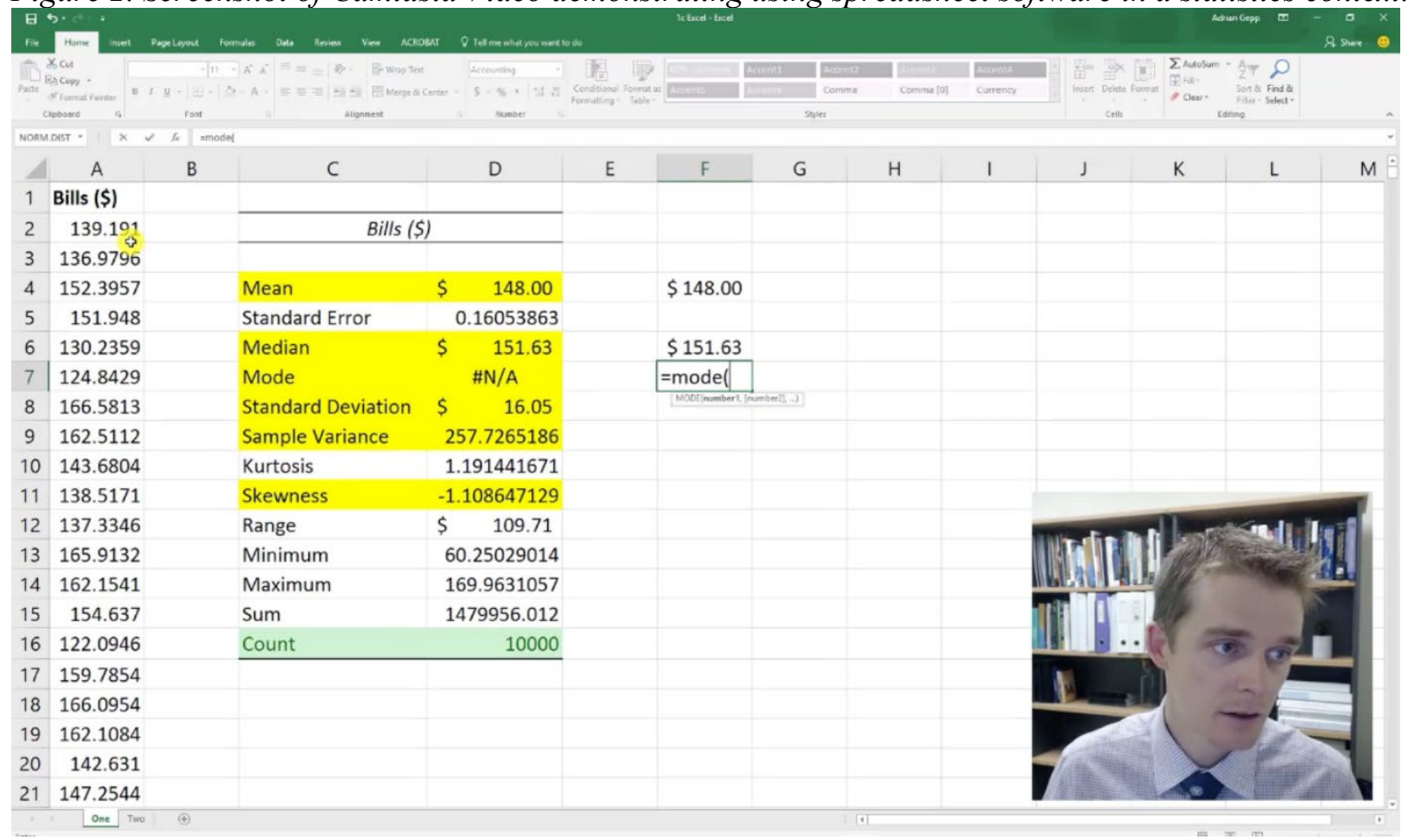

\section{CONCLUSION}

Although there are many blended learning tools that have originated in the last two decades, evaluating the quality of blended learning experiences is not an easy job as tools and technologies only support part of the learning process (Ginns \& Ellis, 2007). Ginns and Ellis (2007) also concluded based on a student survey that educators in blended learning contexts need to focus not only on technical aspects but look into the students' perception of the learning environment and how successfully it supports student learning. Blended learning also brings many challenges to educators, as well as students, as both of them require advanced digital skills to deliver and receive the subject material. 
Much work has been done that pits computers and technology against human intelligence, as exemplified by the Netflix documentary AlphaGo in which a computer competes against the world champion of the board game Go. However, Guszcza \& Schwartz (2019) have called for more efforts being placed on how computers and people can complement each other, instead of focusing on one competing against, or replacing, the other. Consistent with this call, the authors conclude that the application of blended learning tools in teaching can complement the effective learning experience, rather than replace traditional learning methods. However, without proper assessment, education runs the risk of following corporations that are spending large amounts of money on digital transformation without success. In 2018 , it was estimated that $\$ 1.3$ trillion was spent on digital transformation initiatives, but shockingly $\$ 900$ billion of that was estimated to have been wasted (Tabrizi et al., 2019).

In conclusion, educators should be informed of the blended learning tools available and make use of them to complement, not replace, their existing teaching practices. Furthermore, like any data model, teaching styles should be regularly evaluated and modified accordingly so that blended learning efforts are being used in ways that enhance the student learning experience.

\section{REFERENCES}

Boyle, T., Bradley, C., Chalk, P., Jones, R., \& Pickard, P. (2003). Using blended learning to improve student success rates in learning to program. Journal of educational Media, 28(2-3), 165-178.

Chuang, H., Weng, C. \& Chen, C. (2018), Which students benefit most from a flipped classroom approach to language learning?. British Journal of Educational Technology, 49, 56-68

Driscoll, M. (2002). Blended learning: Let's get beyond the hype. E-learning, 3. Retrieved 22 May, 2019, from https://www.researchgate.net/publication/286029739 Blended learning_Let's get beyond the hype

Garrison, D. R., \& Kanuka, H. (2004). Blended learning: Uncovering its transformative potential in higher education. The internet and higher education, 7(2), 95-105.

Ginns, P., \& Ellis, R. (2007). Quality in blended learning: Exploring the relationships between on-line and face-to-face teaching and learning. The Internet and Higher Education, 10(1), 53-64.

Guszcza, J., \& Schwartz, J. (2019). Superminds: How humans and machines can work together. Deloitte Review, 24, 120-131. Retrieved 21 May, 2019, from

https://www2.deloitte.com/content/dam/insights/us/articles/DeloitteReview24/DI DeloitteReview24.pdf

Hart, J. (2019). Top Tools for Learning 2018: Results of the 12th Annual Digital Learning Tools survey. Centre for Learning \& Performance Technologies. Retrieved 20 May, 2019, from https://www.toptools4learning.com/

Horn, M. B., \& Staker, H. (2011). The rise of K-12 blended learning: Profiles of emerging models. Innosight Institute. Retrieved 20 March, 2019, from https://files.eric.ed.gov/fulltext/ED535181.pdf

Kaplanis, D. (2013). 5 Benefits Of The Blended Learning Approach. TalentLMS. Retrieved 12 February, 2018, from https://www.talentlms.com/blog/5-reasons-why-blended-learning-works/

López-Pérez, M. V., Pérez-López, M. C., \& Rodríguez-Ariza, L. (2011). Blended learning in higher education: Students' perceptions and their relation to outcomes. Computers \& Education, 56(3), 818-826.

Oliver, M., \& Trigwell, K. (2005). Can ‘blended learning’be redeemed? E-learning and Digital Media, 2(1), 17-26. 
O'Toole, J. M., \& Absalom, D. J. (2003). The impact of blended learning on student outcomes: Is there room on the horse for two?. Journal of Educational Media, 28(2-3), 179-190.

Staker, H., \& Horn, M. B. (2012). Classifying K-12 Blended Learning. Innosight Institute. Retrieved 20 March, 2019, from https://files.eric.ed.gov/fulltext/ED535180.pdf

Tabrizi, B., Lam, E., Girard, K., \& Irvin, V. (2019). Digital Transformation Is Not About Technology. Harvard Business Review, March 13. Retrieved 5 June, 2019, from https://hbr.org/2019/03/digitaltransformation-is-not-about-technology

Wikipedia (n.d.). Blended Learning. Retrieved from https://en.wikipedia.org/wiki/Blended learning 